\title{
Latent tuberculosis infection among minor asylum seekers in Denmark
}

\author{
To the Editor:
}

We read with interest the study by WolTeRs et al. [1], reporting the results of radiographic tuberculosis (TB) entry screening of asylum seekers in the Netherlands. We agree with the authors that we lack sufficient studies concerning latent TB infection (LTBI) screening among minor asylum seekers, and we present our study investigating LTBI prevalence and the coverage of follow-up in terms of clinical evaluation and treatment of LTBI among minor asylum seekers arriving in Denmark.

In low TB-incidence countries, TB screening among immigrants generally focuses on active TB in adults, and is considered most cost-effective in individuals from regions with a TB incidence $>100 / 100000$ [2-4]. Compared with adults, minors aged $<5$ years with LTBI have an increased risk of TB disease, and minors in general may be at increased risk of disease, because they are most likely to have been exposed recently $[5,6]$. Therefore, screening for and treatment of LTBI could be an appropriate way to prevent active TB [7]. Despite this, there is no consensus regarding LTBI screening among minor immigrants and various approaches have been implemented across Europe [1, 2, 4, 8-10].

In Denmark, all asylum seekers are offered a routine health assessment within 10 days of arrival at the national reception centre Sandholm. A voluntary TB screening is offered for those originating from a high TB-incidence country (>100/100000 per year), or belonging to a TB high-risk group (former stay in a warzone, refugee camp or prison or any known immunosuppressive diseases) [11]. Asylum seekers aged $\geqslant 16$ years are screened for active TB using chest radiography, whereas minors aged $<16$ years are screened for LTBI using a QuantiFERON ${ }^{\circledR}$ test (QFT). All individuals with symptoms of active TB or a positive QFT result are referred to a paediatrician for further evaluation. Danish guidelines recommend treatment of LTBI for all minors aged $<5$ years, whereas treatment decision in minors aged $\geqslant 5$ years is at the discretion of the attending physician [11].

We conducted a retrospective register-based study investigating the prevalence of LTBI among minor asylum seekers arriving in Denmark and aimed to assess the coverage of follow-up in terms of clinical evaluation and treatment of LTBI. We included all asylum seekers with a self-reported age <16 years, screened between April 2017 and August 2018. Migrant groups other than asylum seekers were not included in our study, because these are not routinely offered LTBI screening in Denmark. The study was approved by the Danish Data Protection Agency and the Patient Safety Authority.

During the study period, 224 minors aged $<16$ years were candidates for LTBI screening, and testing was accepted in 175 (78.1\%) individuals, of which 173 (98.9\%) had a determinate result. Of these, 20 (11.6\%) had a positive QFT. Significant risk factors for positive QFT were unaccompanied status, none/unknown bacille Calmette-Guérin vaccination status, travel duration $>70$ days, age $>12$ years and Eastern Mediterranean as region of origin (table 1). Of the 20 minors referred to a paediatrician, six (30.0\%) were lost to follow-up after referral. Of the remaining 14 minors, three had been treated recently for LTBI, explaining their positive QFT. Ultimately, 11 minors were considered to have untreated LTBI, of which five (45.5\%) were offered and completed LTBI treatment; three $(27.3 \%)$ received a follow-up appointment implying a control chest radiography; and three $(27.3 \%)$ did not receive any treatment or follow-up. The physicians' reasons for omitting LTBI treatment were exclusion of active TB with chest radiography, negative induced sputum or gastric lavage, absence of TB symptoms and the risk of isoniazid side-effects.

@ERSpublications

Screening among minor asylum seekers in Denmark revealed a high LTBI prevalence with heterogeneity in terms of clinical evaluation and initiating preventive treatment, underlining the need for uniform management of LTBI screening and treatment http://bit.ly/2m2WyJI

Cite this article as: Ahmad BB, Kristensen KL, Glenthoej JP, et al. Latent tuberculosis infection among minor asylum seekers in Denmark. Eur Respir J 2020; 55: 1901688 [https://doi.org/10.1183/ 13993003.01688-2019]. 


\begin{tabular}{|c|c|c|c|}
\hline & Positive QFT & Negative QFT & p-value $\#$ \\
\hline Total & $20(100)$ & $153(100)$ & \\
\hline \multicolumn{4}{|l|}{ Sex } \\
\hline Male & $16(80.0)$ & 84 (54.9) & \multirow[t]{2}{*}{0.06} \\
\hline Female & $4(20.0)$ & $69(45.1)$ & \\
\hline \multicolumn{4}{|l|}{ Accompanied status } \\
\hline Accompanied & $6(30.0)$ & $133(86.9)$ & \multirow[t]{2}{*}{$<0.001$} \\
\hline Unaccompanied & $14(70.0)$ & $20(13.1)$ & \\
\hline \multicolumn{4}{|l|}{ BCG vaccination } \\
\hline Yes & $7(35.0)$ & 119 (77.8) & \multirow[t]{2}{*}{$<0.001$} \\
\hline No/unknown & $13(65.0)$ & $34(22.2)$ & \\
\hline \multicolumn{4}{|l|}{ Reason for screening } \\
\hline High-incidence country? & $17(85.0)$ & 136 (88.9) & \multirow[t]{2}{*}{0.71} \\
\hline High-risk group ${ }^{+}$ & $3(15.0)$ & $17(11.1)$ & \\
\hline \multicolumn{4}{|l|}{ Travel duration days } \\
\hline $1-5$ & $4(20.0)$ & 65 (42.5) & 0.09 \\
\hline $6-70$ & $1(5.0)$ & $29(19.0)$ & 0.21 \\
\hline$>70$ & $13(65.0)$ & $24(15.7)$ & $<0.001$ \\
\hline Unknown & $2(10.0)$ & $35(22.9)$ & 0.24 \\
\hline \multicolumn{4}{|l|}{ Age at screening years } \\
\hline $0-4$ & $1(5.0)$ & $46(30.1)$ & 0.03 \\
\hline $5-11$ & $3(15.0)$ & $60(39.2)$ & 0.05 \\
\hline $12-15$ & $16(80.0)$ & $47(30.7)$ & $<0.001$ \\
\hline \multicolumn{4}{|l|}{ Region of origin $\S$} \\
\hline Eastern Mediterranean & $13(65.0)$ & $59(38.6)$ & 0.03 \\
\hline Afghanistan & $2(10.0)$ & $26(17.0)$ & $\mathrm{n} / \mathrm{a}$ \\
\hline Syria & $2(10.0)$ & $13(8.5)$ & $\mathrm{n} / \mathrm{a}$ \\
\hline Morocco & $7(35.0)$ & $4(2.6)$ & $\mathrm{n} / \mathrm{a}$ \\
\hline Iraq & $0(0)$ & $10(6.5)$ & $\mathrm{n} / \mathrm{a}$ \\
\hline Libya & $1(5.0)$ & $3(2.0)$ & $\mathrm{n} / \mathrm{a}$ \\
\hline Egypt & $0(0)$ & $2(1.3)$ & $\mathrm{n} / \mathrm{a}$ \\
\hline Algeria & $1(5.0)$ & $1(0.7)$ & $\mathrm{n} / \mathrm{a}$ \\
\hline Europe & $3(15.0)$ & $69(45.1)$ & 0.02 \\
\hline Georgia & $0(0)$ & $38(24.8)$ & $\mathrm{n} / \mathrm{a}$ \\
\hline Russia & $0(0)$ & $9(5.9)$ & $\mathrm{n} / \mathrm{a}$ \\
\hline Armenia & $0(0)$ & $9(5.9)$ & $\mathrm{n} / \mathrm{a}$ \\
\hline Belarus & $0(0)$ & 6 (3.9) & $\mathrm{n} / \mathrm{a}$ \\
\hline Ukraine & $0(0)$ & $6(3.9)$ & $\mathrm{n} / \mathrm{a}$ \\
\hline Azerbaijan & $3(15.0)$ & $0(0)$ & $\mathrm{n} / \mathrm{a}$ \\
\hline Uzbekistan & $0(0)$ & $1(0.7)$ & $\mathrm{n} / \mathrm{a}$ \\
\hline Africa & $4(20.0)$ & $19(12.4)$ & 0.51 \\
\hline Eritrea & $1(5.0)$ & $10(6.5)$ & $\mathrm{n} / \mathrm{a}$ \\
\hline Ethiopia & $2(10.0)$ & $1(0.7)$ & $\mathrm{n} / \mathrm{a}$ \\
\hline Sudan & $0(0)$ & $3(2.0)$ & $\mathrm{n} / \mathrm{a}$ \\
\hline Nigeria & $0(0)$ & $3(2.0)$ & $\mathrm{n} / \mathrm{a}$ \\
\hline Somalia & $1(5.0)$ & $1(0.7)$ & $\mathrm{n} / \mathrm{a}$ \\
\hline Congo & $0(0)$ & $1(0.7)$ & $\mathrm{n} / \mathrm{a}$ \\
\hline South-East Asia & $0(0)$ & 6 (3.9) & 0.61 \\
\hline India & $0(0)$ & $3(2.0)$ & $\mathrm{n} / \mathrm{a}$ \\
\hline Sri Lanka & $0(0)$ & $2(1.3)$ & $\mathrm{n} / \mathrm{a}$ \\
\hline Indonesia & $0(0)$ & $1(0.7)$ & $\mathrm{n} / \mathrm{a}$ \\
\hline
\end{tabular}

Data are presented as $\mathrm{n}(\%)$, unless otherwise stated. QFT: QuantiFERON ${ }^{\circledR}$ test; BCG: bacille CalmetteGuérin; n/a: not applicable. " : p-value $\leqslant 0.05$ (using Chi-squared test) was considered statically significant; ף: defined by a tuberculosis incidence $>100 / 100000 ;{ }^{+}$: former stay in a warzone, refugee camp, prison or any known immunosuppressive diseases; ${ }^{\S}$ : regions modified from [12].

Our study revealed a high prevalence of LTBI when minor asylum seekers from either a high TB-incidence country or belonging to a TB high-risk group were routinely screened. Our results are in line with similar studies among minor asylum seekers in Sweden $(n=2936)$ [8], Germany $(n=968)$ [9] and Spain $(n=373)$ [13], 
which found a LTBI prevalence of $9.5 \%, 6.8 \%$ and $12.7 \%$, respectively. These high prevalences of LTBI in minor asylum seekers arriving in European countries underlines the importance of systematic LTBI screening among minor immigrants. Recently, the European Centre for Disease Prevention and Control (ECDC) published guidelines for the management of LTBI in the European Union [2, 14], concluding that screening of immigrants in general should be considered; however, no specific recommendation was given for minors.

Minor asylum seekers aged $\geqslant 16$ years arriving in Denmark are currently only screened for active TB. This approach neglects the reservoir of LTBI with risk of reactivation in this age group [7]. Other European approaches include LTBI screening for minors aged <18 years [2, 4, 8]. However, no studies have investigated an LTBI screening age limit and evidence-based algorithms for minor adolescents are therefore not available [14].

Our study detected considerable proportions of testing decline (21.9\%), mostly because parents did not consent to blood draw; fear was also mentioned as a reason. Furthermore, we detected a loss to follow-up of $30.0 \%$ after testing positive for LTBI. Asylum seekers in Denmark are free to leave asylum centres whenever they wish to. Some are known to reside as undocumented refugees, others leave the country, explaining the loss to follow-up. Encouragement by healthcare professionals to undergo testing, reduction of disease stigma and the consideration of mandatory testing, which is already done in some European countries [15], may all contribute to maximum detection and treatment of all possible TB and LTBI cases.

Treatment decision in minors aged $\geqslant 5$ years in Denmark is at the discretion of the attending physician, and we identified various approaches in terms of clinical evaluation and treatment. Fewer than half of the minors with a positive QFT were treated for LTBI. This lack of consensus among physicians calls for the development of guidelines with uniform interventions considering the concept "intention to test is intention to treat". One recommendation would be to manage all minor asylum seekers with LTBI or suspected $\mathrm{TB}$ at one specialised paediatric $\mathrm{TB}$ department and complete treatment, before being transferred to other centres.

Treatment of LTBI is highly effective in persons with the highest progression risk to active TB, such as minors aged $<5$ years [7, 11]. Preventive treatment regimens are effective, safe and well-tolerated in minors, and is therefore not an obstacle to treating LTBI in all minors [3, 10]. Current guidelines advise preventive treatment regimens as short as 3 months, and shorter regimens may become available [10]. Furthermore, studies among adult immigrants have shown that high completion rates of LTBI treatment can be achieved [15]. Nevertheless, treatment completion acquires good adherence, possibly only achieved through directly observed treatment, which can become expensive for the host country [10, 15]. We believe that systematic LTBI screening together with a comprehensive follow-up and completion of preventive treatment may contribute to TB elimination by preventing a considerable number of reactivations after arrival in low TB-incidence host countries.

Our study revealed a high LTBI prevalence among minor asylum seekers upon entry in Denmark, underlining the importance of LTBI screening. The investigation revealed unsatisfactory proportions of testing decline, loss to follow-up after testing and heterogeneity in terms of clinical evaluation and initiating preventive treatment. Uniform management of LTBI screening and preventive treatment among minor immigrants are needed to enhance the efforts of accelerating TB elimination in low-TB incidence countries according to ECDC guidelines.

Banoo Bakir Ahmad $\oplus^{1}$, Kristina Langholz Kristensen ${ }^{1,2,3}$, Jonathan Peter Glenthoej ${ }^{4}$, Anja Poulsen ${ }^{5}$, Ann-Gine Bryld ${ }^{6}$, Franziska Grundtvig Huber ${ }^{1}$, Ebbe Munk Andersen ${ }^{6}$ and Pernille Ravn ${ }^{1}$

${ }^{1}$ Dept of Internal Medicine, Section for Infectious Diseases, Herlev-Gentofte Hospital, Hellerup, Denmark.

${ }^{2}$ International Reference Laboratory of Mycobacteriology (IRLM), Statens Serum Institut (SSI), Copenhagen, Denmark.

${ }^{3}$ Dept of Pulmonary and Infectious Diseases, Nordsjaellands Hospital, Hilleroed, Denmark. ${ }^{4}$ Dept of Paediatrics and Adolescent Medicine, Nordsjaellands Hospital, Hilleroed, Denmark. ${ }^{5}$ Dept of Paediatrics and Adolescent Medicine, Rigshospitalet, Copenhagen, Denmark. ${ }^{6}$ Red Cross Denmark, Health Unit, Asylum Dept, Copenhagen, Denmark.

Correspondence: Banoo Bakir Ahmad, Dept of Internal Medicine, Section for Infectious Diseases, Herlev-Gentofte Hospital, Kildegaardsvej 28, Hellerup, 2900 Denmark. E-mail: banoo.bakir.ahmad.01@regionh.dk

Received: 13 June 2019 | Accepted after revision: 18 Sept 2019

Conflict of interest: B.B. Ahmad has nothing to disclose. K.L. Kristensen has nothing to disclose. J.P. Glenthoej has nothing to disclose. A. Poulsen has nothing to disclose. A-G. Bryld has nothing to disclose. F.G. Huber has nothing to disclose. E.M. Andersen has nothing to disclose. P. Ravn reports personal fees for lectures from MSD and AbbVie, personal fees for data monitoring committee work from Statens Serum Institute, grants from Gilead, and has had a research collaboration with Astellas, outside the submitted work; and has a patent IP 10 for TB diagnosis issued. 


\section{References}

1 Wolters BA, Akkerman OW, Aartsma Y, et al. Impact of radiographic screening of $>34000$ asylum seeker children. Eur Respir J 2019; 54: 1900579.

2 European Centre for Disease Prevention and Control. Public Health Guidance on Screening and Vaccination for Infectious Diseases in Newly Arrived Migrants Within the EU/EEA. 2018. www.ecdc.europa.eu/sites/default/files/ documents/Public\%20health\%20guidance\%20on\%20screening\%20and\%20vaccination\%20of\%20migrants\%20in\% 20the\%20EU\%20EEA.pdf

3 World Health Organization. Latent Tuberculosis Infection - Updated and Consolidated Guidelines for Programmatic Management. 2018. http://apps.who.int/iris/bitstream/handle/10665/260233/9789241550239-eng. pdf? sequence=1 Date last accessed: November 17, 2018.

4 Kunst H, Burman M, Arnesen TM, et al. Tuberculosis and latent tuberculous infection screening of migrants in Europe: comparative analysis of policies, surveillance systems and results. Int J Tuberc Lung Dis 2017; 21: 840-851.

5 Marais BJ. Tuberculosis in children. J Paediatr Child Health 2014; 50: 759-767.

6 Alvarez GG, Clark M, Altpeter E, et al. Pediatric tuberculosis immigration screening in high-immigration, low-incidence countries. Int J Tuberc Lung Dis 2010; 14: 1530-1537.

7 Ritz N, Brinkmann F, Santiago Garcia B, et al. Tuberculosis in young refugees. Lancet 2015; 386: $2475-2476$.

8 Bennet R, Eriksson M. Tuberculosis infection and disease in the 2015 cohort of unaccompanied minors seeking asylum in Northern Stockholm, Sweden. Infect Dis 2017; 49: 501-506.

9 Mueller-Hermelink M, Kobbe R, Methling B, et al. Universal screening for latent and active tuberculosis (TB) in asylum seeking children, Bochum and Hamburg, Germany, September 2015 to November 2016. Euro Surveill 2018; 23:

10 Carvalho I, Goletti D, Manga S, et al. Managing latent tuberculosis infection and tuberculosis in children. Pulmonology 2018; 24: 106-114

11 Kruse A, Hvass A, Wejse C, et al. 2018. Tuberkulosebekæmpelse i Danmark. Et Nationalt Tuberkuloseprogram. [Fighting Tuberculosis in Denmark. A National Tuberculosis Programme]. www.infmed.dk/download? $\mathrm{UID}=41 \mathrm{f} 431506 \mathrm{dbd} 2 \mathrm{~b} 270 \mathrm{~d} 2 \mathrm{c} 88487 \mathrm{fc} 5121 \mathrm{e} 7 \mathrm{cc} 66 \mathrm{~b} 56$.

12 World Health Organization (WHO). World Health Organization Global Tuberculosis Report 2018. Geneva, WHO, 2018. http://apps.who.int/medicinedocs/en/m/abstract/Js23553en/

13 Belhassen-García M, Pérez Del Villar L, Pardo-Lledias J, et al. Imported transmissible diseases in minors coming to Spain from low-income areas. Clin Microbiol Infect 2015; 21: 370.

14 European Centre for Disease Prevention and Control. Programmatic Management of Latent Tuberculosis Infection in the European Union. 2018. https://ecdc.europa.eu/sites/portal/files/documents/October-2018-Programmaticmanagement-LTBI-EU.pdf

15 Schein YL, Madebo T, Andersen HE, et al. Treatment completion for latent tuberculosis infection in Norway: a prospective cohort study. BMC Infect Dis 2018; 18: 587. 